\title{
Preparation and Barrier Properties of Chitosan- Layered Silicate Nanocomposite Films
}

\author{
Hale Oguzlu, Funda Tihminlioglu*
}

Summary: In this study, chitosan nanocomposite films were prepared using a solvent-casting method by incorporation of an organically modified montmorillonite (Cloisite 10A). The effect of filler concentration on the water vapor permeability, oxygen permeability, mechanical and thermal properties of the composite films was evaluated. The structure of nanocomposites and the state of intercalation of the clay were characterized by XRD. The water vapor permeability of pure chitosan films was measured as a function of relative humidity (RH). It was found that the permeability value increased with an increase in $\mathrm{RH}$. The water vapor and gas permeability values of the composite films decreased significantly with increasing filler concentration. Permeation data was fitted to various phenomenological models predicting the permeability of polymer systems filled with nanoclays as a function of clay concentration and aspect ratio of nanoplatelets. According to the XRD results, an increase in basal spacing was obtained with respect to pure clay for chitosan/clay nanocomposites. This demonstrated the formation of intercalated structure of clay in the polymer matrix. Tensile strength and elongation at break of the composites increased significantly with the addition of clay, however the thermal and color properties of the films were not much affected by the intercalation of clay into polymer matrix.

Keywords: chitosan; layered silicate; oxygen permeability; polymer nanocomposites; water vapor permeability

\section{Introduction}

Use of natural polymers, such as proteins and polysaccharides, as coating or film materials for protection of food has grown extensively in recent years. Chitosan is one of the most abundant natural biopolymers and a partially deacetylated derivative of chitin. ${ }^{[1]}$ Because of its good film-forming properties, it is especially used as edible films and coatings for instance the storage of fruits and seafood products. ${ }^{[2-3]}$ However, the main drawback in these applications is the high water permeability and low water resistance at high relative humidity

\footnotetext{
Department of Chemical Engineering, Izmir Institute of Technology, Gülbahce Urla, İzmir 35430, Turkey E-mail: fundatihminlioglu@iyte.edu.tr
}

conditions due to large number of hydrogen bonds existing in chitosan. ${ }^{[4]}$

Reinforcing fillers such as layered silicates can be used to improve water-resistance and water vapor barrier properties of chitosan films. The most widely used layered silicates are montmorillonite clays having nano-scale dimensions. Unique improvements brought in by clay nanoplatelets intercalated or exfoliated within the polymer matrix were well reviewed in the literature. Improved elastic modulus and tensile strength at break due to strong interactions between high surface area of layered silicate and polymer matrix and improvements in barrier properties due to enhanced tortuosity are also promising features of biopolymer nanocomposites. ${ }^{[5-7]}$ The decrease in barrier properties of polymer nanocomposite films is believed to be due to the presence of 
ordered dispersed clay nanoparticle layers with large aspect ratios in the polymer matrix. This causes an increase in effective path length for diffusion of water vapour and gas into the polymer matrix. By fitting permeation data to various phenomenological models, the aspect ratio can be estimated. ${ }^{[8-10]}$

The aim of this study was to investigate the influence of relative humidity on the water vapor permeability of chitosan and the effect of nanofiller content on the water vapor and oxygen permeabilities of the chitosan nanocomposite films. Furthermore, the experimental permeability data was fitted to various permeability models. The aspect ratio was predicted based on the best fitting model to the experimental data. The effect of clay loading on the thermal, mechanical and color properties of chitosan nanocomposite films was also examined.

\section{Experimental Part}

\section{Materials}

Chitosan powder purchased from Aldrich had a degree of deacetylation of $85 \%$ (low molecular weight and viscosity of 20,000 cps) Glacial acetic acid with $99.7 \%$ purity and molecular weight of $60.05 \mathrm{~g} / \mathrm{mole}$ purchased from Panreac was used as a solvent. The nanoclay under the trade name Cloisite 10A was supplied from Southern Clay Products Inc. $\left(\rho=1.90 \mathrm{~g} / \mathrm{ml}, \mathrm{d}_{001}=19.2 \AA\right.$ 自 $)$ with a cationic exchange capacity (CEC) of 125 mequiv/100 g. It is a natural montmorillonite modified with a quaternary ammonium salt (dimethyl, benzyl, hydrogenated tallow, quaternary ammonium).

\section{Preparation of Pure Chitosan Films}

Chitosan films were prepared by using a $1 \mathrm{v} / \mathrm{v} \%$ aqueous acetic acid solution containing $3(\mathrm{w} / \mathrm{v}) \%$ chitosan $(100 \mathrm{ml})$. The polymer solution was prepared by dissolving chitosan in aqueous acetic acid on a magnetic stirrer for $24 \mathrm{hrs}$, then the solution was cast onto to polystyrene petri dishes. The films were dried at $50{ }^{\circ} \mathrm{C}$ and kept in a desiccator until use.

\section{Preparation of Chitosan Nanocomposite Films}

Solvent intercalation was used for the preparation of chitosan nanocomposite films. In this technique, layered silicates were swollen in the solvent system, then the polymer solution was mixed with the claysolvent dispersion. Clay dispersions with various clay contents were prepared by dispersing appropriate amounts of clay in aqueous acetic acid through stirring for $2 \mathrm{hrs}$. Then, sonication was applied for $1 \mathrm{hr}$. This clay dispersion was added slowly to the chitosan solutions and $2 \%, 4 \%, 8 \%$ and $10 \%(w / w)$ clay loadings with respect to chitosan (2 wt \% solution) were obtained. The final solutions were sonicated again for $1 \mathrm{hr}$. Finally, films were cast on polystyrene petri dishes. The films were dried at $50{ }^{\circ} \mathrm{C}$ and kept in a desiccator until use.

\section{Characterization}

\section{X-ray Diffraction (XRD)}

The structure of nanocomposites and the state of intercalation of the clay were characterized with Phillips X'Pert Pro MRD with $\mathrm{Cu} \mathrm{K} \alpha$ radiation $(\lambda=1.54 \mathrm{~nm})$ under a voltage of $40 \mathrm{kV}$ and a current of $40 \mathrm{~mA}$. Samples were scanned for diffraction angles $2 \theta=0.25-30^{\circ}$.

\section{Thermal Properties}

Thermal properties of the film samples were measured by differential scanning calorimetry DSC, TA instruments Q10; nitrogen flow of $50 \mathrm{~mL} / \mathrm{min}$; samples $(3 \mathrm{mg}$ ) were scanned at a rate of $10^{\circ} \mathrm{C} / \mathrm{min}$ between 10 and $550{ }^{\circ} \mathrm{C}$.

\section{Mechanical Properties}

Tensile strength and elongation at break of each film sample were measured with a testometric M500-1000KN instrument (ASTM D 882). Load cell capacity was $100 \mathrm{Kf}$. Specimens were prepared $10 \mathrm{~mm}$ in width. Initial gauge length and cross-head speed were set at $50 \mathrm{~mm}$ and $5 \mathrm{~mm} / \mathrm{min}$, respectively. From the strain-stress data, tensile strength and elongation at break of 
the films were calculated. A total of five samples were tested for each film sample and the average values are reported.

\section{Color Measurements}

The color of chitosan nanocomposite films was assessed using a colorimeter (Avantes). Pure chitosan $(\mathrm{L}=82.82, \quad \mathrm{a}=-2.85$, $\mathrm{b}=12.64)$ film was used as a background for color measurements of the nanocomposite films. According to Hunter system; $\mathrm{L}$, $\mathrm{a}$, and $\mathrm{b}$ values were averaged from three readings across for each film. In this system, color is represented as a position in a threedimensional sphere, where the vertical axis $\mathrm{L}$ indicates the lightness (ranging from black to white), and the horizontal axes, indicated by $a$ and $b$, are the chromatic coordinates (ranging from a: greenness to redness and b: blueness to yellowness). The total color difference $(\Delta \mathrm{E})$ can be calculated with the following Equation (1):

$$
\Delta E=\sqrt{(\Delta L)^{2}+(\Delta a)^{2}+(\Delta b)^{2}}
$$

\section{Barrier Properties}

\section{Water Vapor Permeability}

Mocon Permatran-W model ${ }^{\mathbb{R}} 3 / 33$ water vapor permeation measurement system was used in order to analyze and measure the water vapor transmission rate of the film samples. The instrument uses a infrared sensor to detect water vapor transmission through the films. Measurements were performed at $37.8^{\circ} \mathrm{C}$ using a nitrogen gas with a flow rate of $100 \mathrm{~cm}^{3} / \mathrm{min}$. The water vapor transmission data was measured at different relative humidity values (35-90\% $\mathrm{RH})$ for pure chitosan films while relative humidity was set to $90 \%$ for chitosan nanocomposite films (ASTM F 1249). The water vapor permeability of the films was calculated by using Equation (2) given below:

\section{Permeability}

$$
=\frac{\text { Trasmission Rate }}{\Delta P} x \text { Thickness }
$$

\section{Gas Permeability}

The oxygen permeability of the films was measured according to the ASTM D3985 standard using gas permeation instrument, Lyssy L100-5000 (PBI Dansensor, Denmark) based on the manometric testing principle. In the manometric testing method, a pressure difference (driving force) across the sample is created by maintaining the test gas at atmospheric pressure in the upper chamber, while vacuum is applied in the lower measuring chamber. As the gas permeates through the sample, the pressure in the lower measuring chamber increases. The instrument measures the time required for the lower chamber pressure to increase from a predefined lower limit to a pre-defined upper limit. The measured time interval is then transformed into the gas permeability rate expressed in $\mathrm{ml} / \mathrm{m}^{2} /$ day. Gas permeabilities of the films were determined at constant temperature $\left(23^{\circ} \mathrm{C}\right)$ and relative humidity $(0 \% \mathrm{RH})$ conditions with $5-10 \mathrm{~cm}^{3} / \mathrm{min}$ gas flow.

\section{Results and Discussion}

\section{Characterization}

Figure 1 shows the XRD patterns of Cloisite $10 \mathrm{~A}$ and chitosan nanocomposite films. The basal spacing ( $d$-spacing) of pure clay has been calculated as $1.92 \mathrm{~nm}$ from a diffraction peak at $2 \theta=4.7^{\circ}$ (characteristic peak of the clay) using Bragg function (shown in inset of Figure 1). The characteristic peak of the clay disappears in the XRD spectrum for chitosan nanocomposite films when the clay content is $2 \mathrm{wt} \%$, which could show the formation of exfoliated structure of clay. The diffraction peaks of the nanocomposite films with 4 to $10 \mathrm{wt} \%$ clay are shifted to slightly lower angles $\left(2 \theta=4.3^{\circ}\right)$ showing a partially intercalated structure with a slight increase in the dspacing of about $2.05 \mathrm{~nm}$.

The results indicate that the layered clay is delaminated in the chitosan solution when the clay content is relatively low ( $2 \mathrm{wt} \%)$, whereas the intercalated structure 


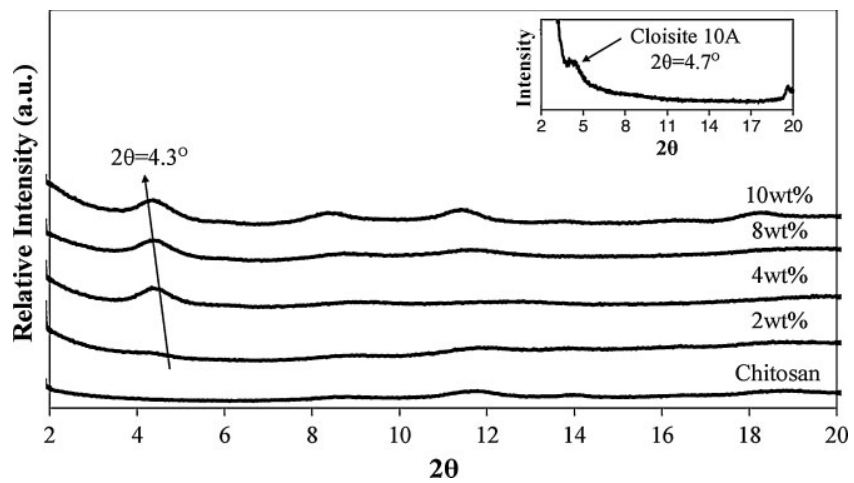

Figure 1.

XRD patterns of Cloisite $10 \mathrm{~A}$, pure chitosan and chitosan nanocomposite films.

is dominant partially when clay content is higher than $2 \mathrm{wt} \%$ clay in the chitosan polymer matrix.

\section{Thermal Properties}

DSC plots of pure chitosan, $2 \mathrm{wt} \%$ and $10 \mathrm{wt} \%$ Cloisite $10 \mathrm{~A}$ incorporated films are presented in Figure 2. One endothermic and one exothermic peak were detected by the DSC for both pure chitosan and nanocomposite films. The first endothermic peak that occurs over the temperature range of $91-125^{\circ} \mathrm{C}$ was attributed to the solvent and water evaporation while the exothermic peaks indicate the degradation temperatures of polymer and polymer nanocomposites.

All chitosan films were degraded at 284$297^{\circ} \mathrm{C}$, which agrees well with the results reported in the literature. ${ }^{[11,12]}$ The addition of nanoclay into chitosan slightly lowered the degradation temperature. No melting peak of chitosan was observed showing the amorphous structure of the chitosan used in this study. The DSC results of the all films are included in Table 1.

\section{Mechanical Properties}

The effect of clay addition on the mechanical properties of the chitosan nanocompo-

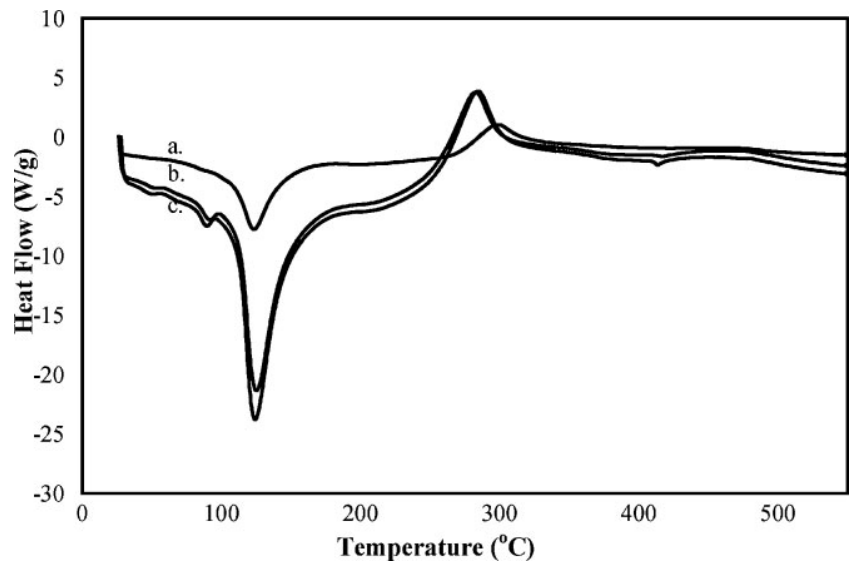

Figure 2.

DSC thermographs of (a) pure chitosan, (b) 2 wt \% and (c)10 wt \% Cloisite 10A loaded chitosan nanocomposite films. 
Table 1.

Thermal and mechanical properties of the chitosan films.

\begin{tabular}{lcccc}
\hline Samples & $\begin{array}{c}\text { Endothermic } \\
\text { Peak }\left({ }^{\circ} \mathrm{C}\right)\end{array}$ & $\begin{array}{c}\text { Exothermic } \\
\text { Peak }\left({ }^{\circ} \mathrm{C}\right)\end{array}$ & $\begin{array}{c}\text { Strain at } \\
\text { Break (\%) }\end{array}$ & $\begin{array}{c}\text { Tensile } \\
\text { Strength (MPa) }\end{array}$ \\
\hline Pure chitosan & 123.85 & 297.56 & 1.70 & 43.33 \\
Chitosan/2 wt \% clay & 125.55 & 282.13 & 2.90 & 54.55 \\
Chitosan/4 wt \% clay & 121.89 & 268.42 & 2.10 & 55.56 \\
Chitosan/8 wt \% clay & 129.26 & 286.28 & 1.75 & 60.00 \\
Chitosan/10 wt \% clay & 124.50 & 283.89 & 2.50 & 77.78 \\
\hline
\end{tabular}

site films has been investigated. Mechanical properties of the chitosan films are summarized in Table 1. The pure chitosan film has a tensile strength of $43.3 \mathrm{MPa}$ and strain at break of $1.70 \%$. Tensile strengths of the nanocomposite films increases significantly with increasing amount of Cloisite 10A. As can be seen from Table 1, tensile strength and strain at break values of nanocomposite films are higher than those of pure chitosan. An increase of approximately $80 \%$ in tensile strength and of $50 \%$ in strain at break was obtained for $10 \mathrm{wt} \%$ loaded nanocomposite films compared to pure chitosan films. The improvement in tensile strength can be described as the formation of an exfoliated/intercalated state and the uniform dispersion of clay in the chitosan matrix or the strong interaction between chitosan and clay. ${ }^{[9]}$

\section{Color Measurements}

The results of the color measurements of the films are shown in Table 2. All films were transparent with a slightly yellowish color. All films have light transmissions in the range of $75-80 \%$ between the wavenumber of $500-700 \mathrm{~cm}^{-1}$. As can be seen from Table 2, the presence of clay in chitosan matrix has almost no effect on the color of the films. It is generally known that
$\Delta \mathrm{E}<3-4$ means that the color change cannot be detected by naked human eyes. Therefore, the results indicate that the dispersion of clay in the polymer matrix can be assumed to be uniform especially up to $8 \mathrm{wt} \%$. loading; for $10 \mathrm{wt} \%$ loaded samples, $\Delta \mathrm{E}$ is around 5.3 .

\section{Water Vapor Permeability (WVP)}

The water vapor permeability of the pure chitosan and nanocomposite films has been investigated. Since chitosan is a water sensitive polymer, the effect of $\mathrm{RH}$ on the water vapor permeability was investigated first. As can be seen in Figure 3, the water vapor permeability of chitosan increases with an increase in relative humidity. The increase was very sharp at $50 \% \mathrm{RH}$.

WVP of the chitosan nanocomposite films was significantly reduced even in the $2 \mathrm{wt} \%$ clay containing chitosan film (Figure 4). Moreover, the WVP decreased as the clay content increased in polymer matrix. WVP of pure chitosan was found to be $3.4 \mathrm{~g} \mathrm{~mm} / \mathrm{m}^{2}$ day $\mathrm{mmHg}$ which is very close to results obtained by Kittur et. al (1998) at $93 \% \mathrm{RH}^{[13]}$ The WVP of the composite films decreased up to $2.4 \mathrm{~g} \mathrm{~mm} /$ $\mathrm{m}^{2}$ day $\mathrm{mmHg}, 20-27 \%$ depending on the clay loading.

Table 2.

The effect of clay loading on color of the chitosan films.

\begin{tabular}{lcccc}
\hline Sample & $\Delta \mathrm{L}$ & $\Delta \mathrm{a}$ & $\Delta \mathrm{b}$ & $\Delta \mathrm{E}$ \\
\hline Chitosan & $82.73 \pm 0.68$ & $-2.82 \pm 0.12$ & $12.61 \pm 0,67$ & - \\
Chitosan/2 wt \% & $84.74 \pm 0.34$ & $-2.68 \pm 0.09$ & $12.70 \pm 0.30$ & $2.00 \pm 0.33$ \\
Chitosan/4 wt \% & $85.74 \pm 0.34$ & $-2.28 \pm 0.13$ & $11.11 \pm 0.38$ & $3.41 \pm 0.22$ \\
Chitosan/8 wt \% & $84.80 \pm 0.90$ & $-2.58 \pm 0.85$ & $13.12 \pm 0.92$ & $2.14 \pm 1.09$ \\
Chitosan/10 wt \% & $85.75 \pm 0.22$ & $-3.37 \pm 0.12$ & $17.02 \pm 0.21$ & $5.37 \pm 1.49$ \\
\hline
\end{tabular}




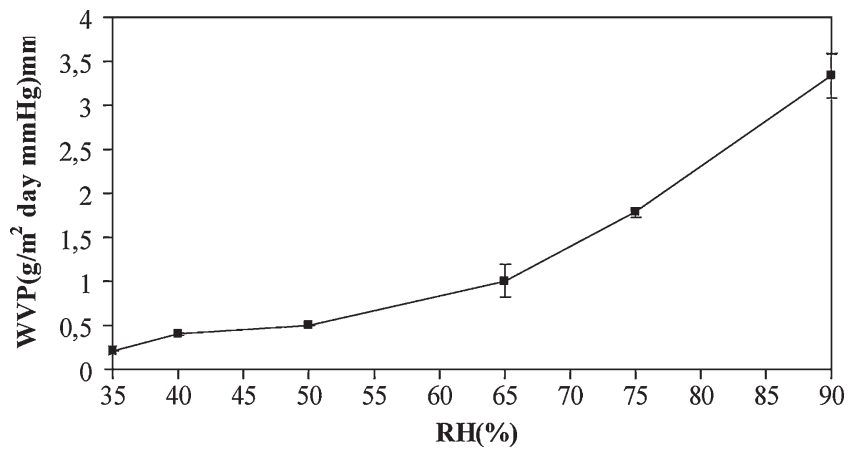

Figure 3.

Water vapor permeability of pure chitosan with respect to relative humidity.

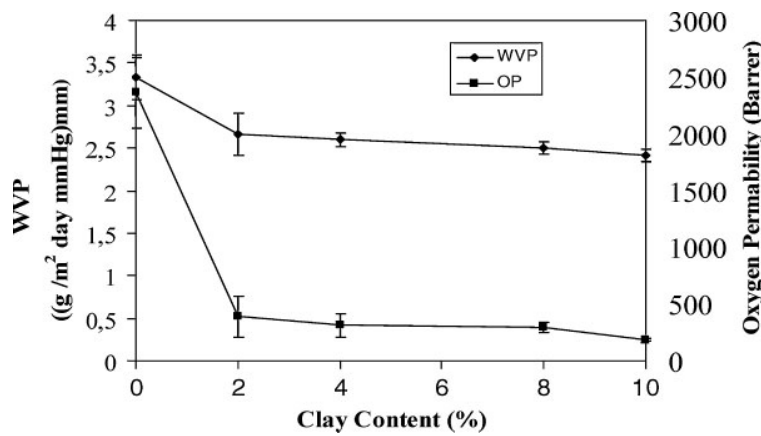

Figure 4 .

Water vapor permeability and oxygen permeability of the chitosan films with respect to clay content.

\section{Oxygen Permeability}

Figure 4 presents oxygen permeation results of the chitosan films. The oxygen permeability of pure chitosan was found to be $1.55 \times 10^{5} \mathrm{ml} \cdot \mathrm{mm} \cdot \mathrm{m}^{-2}$.day ${ }^{-1} \cdot \mathrm{atm}^{-1}$ (2350 barrer) at $23{ }^{\circ} \mathrm{C}, 0 \% \mathrm{RH}$. This value is comparable to that of Kittur et. al (1998) ${ }^{[13]}$ as $8.84 \times 10^{6} \mathrm{ml} \cdot \mathrm{mm} \cdot \mathrm{m}^{-2} \cdot \mathrm{day}^{-1} \cdot \mathrm{atm}^{-1}$ at $27{ }^{\circ} \mathrm{C}$. For all clay loadings the nanocomposite films were better oxygen barriers than the pure chitosan film, exhibiting 83 $92 \%$ reduction in oxygen permeability with the addition of $2-10 \mathrm{wt} \%$ clay into chitosan. In general, clay incorporation decreased the permeability of the nanocomposite films to both water vapor and oxygen.

The decrease in permeabilities of nanocomposite films is believed to be due to the presence of ordered dispersed particle layers with large aspect ratios in the polymer matrix. This forces water vapor to follow a tortuous path through the polymer matrix surrounding the clay particles by increasing the effective path length for diffusion. ${ }^{[14]}$

As a consequence of the permeability studies, the barrier properties of chitosan for use in food packaging, protective coating and other applications can be improved with the addition of clay to the polymer matrix.

Several models have been proposed to predict the effective permeability through nanocomposite polymer films. ${ }^{[10,15-17]}$ The dramatic improvement of barrier properties in these models was explained by the concept of tortuous paths. That is, when impermeable nanoparticles are incorporated into a polymer, the permeating molecules are forced to wiggle around them in a random walk, and hence diffuse 
by a tortuous pathway. In layered silicate polymer nanocomposite systems, the degree of exfoliation or intercalation and state of dispersion of layered silicates in the polymer matrix are the important factors that affect the barrier properties of the layered silicate nanocomposite films. However, for each clay-polymer system, these properties are differing with varying clay content and it is difficult to determine the degree of exfoliation and the aspect ratio according to the barrier properties of nanocomposite. These predictive models can be used to fit the experimental permeability data to various phenomenological models, predicting the permeability of polymer systems filled with nanoclays as a function of clay concentration and aspect ratio of nanoplatelets. The volume fraction of impermeable filler (Cloisite10) was calculated using the Equation (3):

$\phi=\frac{1}{1+\left(\rho_{c} \frac{\left(1-M_{C}\right)}{\rho_{P} M_{C}}\right)}$

where $\rho_{\mathrm{c}}$ and $\rho_{\mathrm{p}}$ are the density of clay and density of polymer, respectively. $\mathrm{M}_{\mathrm{c}}$ refers mass fraction of clay in the polymer matrix.

Figure 5 shows the relative water vapor permeability and oxygen permeability of the chitosan films, as a function of volume fraction of clay, $\phi$. Both water vapor and oxgen experimental permeability data was used for fitting some of these models. The Nielsen Model fitted well to our water vapor and oxygen permeability data. According to the model the effective aspect ratio of nanocomposites was estimated to be between 53 and 2375 from water vapor and oxygen permeability data, which is in good agreement with the reported aspect ratio range (10-1000) for layered silicates. ${ }^{[15-17]}$

\section{Conclusion}

Exfoliated nano-structures were formed upon incorporation of small amounts of Cloisite 10A $(2 \mathrm{wt} \%)$ in the chitosan matrix, whereas the intercalated structure becomes dominant when clay content is higher than $2 \mathrm{wt} \%$. An increase in basal spacing was obtained with respect to pure clay in CSNFs which proves the intercalated structure. Clay loading improves the mechanical and barrier properties of CSNFs. However, the degradation temperature of the nanocomposite films is slightly decreased with increasing clay loading. The water vapor permeability values of chitosan were found to be very sensitive to relative humidity. Above 50\% $\mathrm{RH}$, the permeability values increase very sharply. The water vapor and oxygen permeabilities of the films were reduced by incorporation of clay particles because of the tortuosity of permeable channel increased with the increase of clay concentration. The best fit of our experimental permeability data was obtained using the Nielsen permeability model. As a consequence of the permeability studies, the barrier properties of chitosan for use in

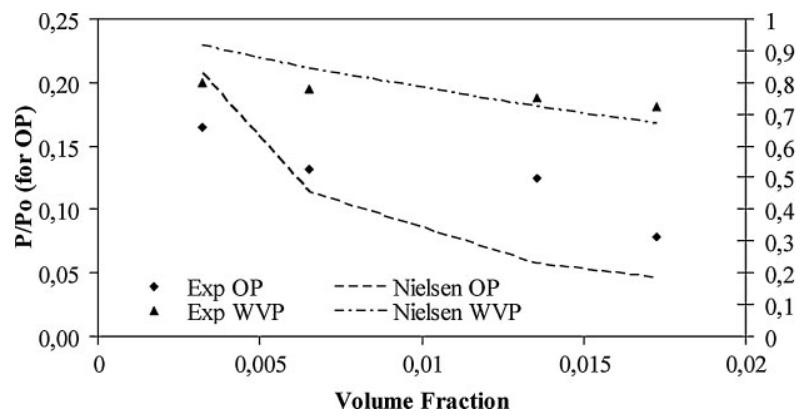

Figure 5.

Relative water vapour and oxygen permeability of chitosan films. 
food packaging, protective coating and other applications can be improved with the addition of clay into the polymer matrix.

Acknowledgements: The authors are grateful to Prof. Dr. Orhan Öztürk in the Physics Department of İzmir Instititute of Technology for XRD characterization of the samples.

[1] N. V. Majeti, R. Kumar, React. Funct. Polym. 2000, 127.

[2] R. V. Tui, P. Fowler, M. Lowther, C. J. Weber, Food Addit Contam, Part A, 2002, 19(4), 172-177.

[3] Y. J. Jeon, J. Y. V. A. Kamil, F. Shanidi, J. Agric. Food Chem. 2002, 50, 5167-5178.

[4] S. Khamhan, Y. Baimark, S. Chaichanadee, P. Phinyocheep, S. Kittipoom, Int J Polym Anal Ch 2008, 13, 224-231.

[5] Q. H. Zeng, A. B. Yu, G. O. Lu, D. R. Paul, J.Nanosci Nanotechno 2005, 5, 1574-1592.
[6] S. Ray, M. Bousmina, Prog Mater Sci. 2005, 50, 9621079.

[7] J. H. Koo, "Polymer nanocomposites: processing, characterization, and applications", Mc Graw Hill, USA 2006.

[8] L. Sun, W. J. Boo, A. Clearfield, H. J. Sue, 135. J. Membrane Sci. 2008, 318, 129-136.

[9] J. P. Zheng, P. Li, Y. L. Ma, K. D. Yao, J. Appl. Polym. Sci. 2002, 86, 1189.

[10] G. Choudalakis, A. D. Gotsis, Eur Polym J, 2009, 45(4), 967-984.

[11] Y. Xu, X. Ren, A. Milford, J Appl Polym Sci, 2006, 99, 1684-1691.

[12] A. Casariego, B. W. S. Souza, A. Vicente, J. A. Teixeira, L. Cruz, R. Diaz, Food Hydrocolloids. 2008, 22, 1452-1459.

[13] F. S. Kittur, K. R. Kumar, R. N. Tharanathan, Lebensm Unters Forsch A, 1998, 206, 44-47.

[14] J. W. Rhim, K. W. H. G. Perry, Crit Rev Food Sci Nutr, 2007, 47, 411-433.

[15] B. Xu, O. Zheng, Y. Song, Y. Shangguan, Polymer 2006, 47(8), 2904-2910.

[16] E. L. Cussler, S. E. Hughes, W. J. Ward, R. Aris, J. Membrane Sci. 1988, 38(2), 275-288.

[17] L. Chunsheng, M. Yiu-Wing, Compos Sci Technol. 2007, 2895-2902. 